\title{
Assessing Social Carrying Capacity of Tourism Destinations with Random Utility Models"
}

\author{
JUAN L. EUGENIO-MARTIN \\ Instituto Universitario de Turismo y Desarrollo Económico Sostenible (TIDES), UNIVERSIDAD \\ DE LAS PALMAS DE GRAN CANARIA, ESPAÑA. E-mail: jleugenio@daea.ulpgc.es
}

\begin{abstract}
Some local visitors or tourists avoid visiting resorts because they have experienced or anticipate overcrowding. Hence, policymakers are concerned to monitor congestion levels. The paper proposes the use of the elasticity of the probability of visiting a destination with respect to increases in congestion, from a random utility framework. More precisely, random parameter logit model is estimated. The advantage of this approach is that it captures not only the current level of congestion but other aspects, such as the sensitivity of different destinations towards crowding and different visitors' concern about congestion and their probabilities of visiting alternative destinations. It is shown that the rate of change of the elasticity increases with the number of visitors, capturing the expected underlying non-linear relationship such that, when the number of visitors is low, the index is also low but increases exponentially with the influx of new visitors.
\end{abstract}

Keywords: Congestion, Carrying Capacity, Destination Choice, Elasticity, Tourism.

\section{Evaluación de la capacidad de carga social de los destinos turísticos con modelos de utilidad aleatoria}

\section{RESUMEN}

Algunos individuos prefieren evitar ciertos destinos porque han experimentado o anticipan que pueden experimentar congestión en el destino. Por lo tanto, es necesario ser consciente del coste provocado por la congestión social y las diferentes necesidades de distintos visitantes para maximizar su satisfacción en relación a la calidad de la experiencia. Este artículo propone el uso de la elasticidad de la probabilidad de visitar un destino en relación a incrementos en el nivel de congestión. La estimación se basa en un modelo de utilidad aleatoria, en particular, un Modelo Logit Mixto. La ventaja de este tipo de modelización es que es capaz de tener en cuenta no sólo el nivel de congestión sino otros aspectos como la sensibilidad de los distintos destinos hacia la congestión, la heterogeneidad de los visitantes en relación al nivel de congestión, y la posibilidad de escoger otros destinos. Este método muestra que la tasa de crecimiento de la elasticidad sigue creciendo ante el incremento de turistas o visitantes, lo que permite capturar la relación latente del modelo que consiste en que cuando el número de turistas sea bajo el índice sea bajo y que crezca exponencialmente con la llegada de turistas.

Palabras clave: Congestión, capacidad de carga, elección del destino, elasticidad, turismo.

Clasificación JEL: L83, C35, Q56

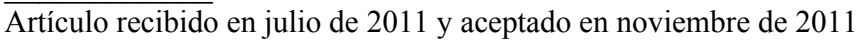

Artículo disponible en versión electrónica en la página www.revista-eea.net, ref. ə-29317 


\section{INTRODUCTION}

Some individuals prefer to avoid destinations because they have experienced or anticipate overcrowding. As a result they may look for alternative destinations or other leisure activities. Thus, awareness of the social congestion cost and the different needs of different visitors are necessary for maximising satisfaction in terms of the quality of the experience (Richardson, 2002) and the likelihood of repeat visits. For this purpose, congestion levels may be monitored (Prato, 2001; Lawson et al., 2003). A possible way of measuring congestion is by counting the number of visitors in peak time and dividing it by some physical attribute of the site, such as the length of paths. However such a measure is independent of alternative destinations and is linear, ignoring saturation effects in the destinations. If this measure is used to monitor congestion levels, all visitors are considered similarly sensitive to congestion. In fact, there is heterogeneity in the way that people perceive congestion (Jakus and Shaw, 2003) and congestion has different relevance and affects different visitors to different degrees (McConnell, 1977; Freeman III and Haveman, 1977; McConnell, 1988; Jakus and Shaw, 1997). Moreover, the sensitivities of different destinations to changes in congestion levels differ (Boxall et al., 2003). This paper proposes a measure to assess current congestion levels that takes into account the capacity of the site, heterogeneous tastes for congestion, probabilities of visiting alternative sites and the overall sensitivity towards congestion. For this purpose, demand is modelled under a random parameters logit model (Train, 1998) and the elasticity of the probability of visiting a particular destination is employed. This paper is applicable to any set of alternative destinations whose enjoyability is negatively affected by congestion. For instance, it may be applied to a set of outdoor recreation activities.

When arguing about congestion cost, it is convenient to decompose it between social congestion cost and environmental congestion cost. The former is referred to when analysing how enjoyability of visitors is affected by congestion (Saveriades, 2000), whereas the latter considers the effects of congestion on the environment (Fisher and Krutilla, 1972). This paper is dedicated to the role of social congestion for outdoor recreation and rural tourism demand. It seems obvious that there exists a negative relationship between overcrowd and the satisfaction of a visit. Although we need to point out that for different activities, crowding has different relevance and its effect is appreciated with different intensity by different visitors, (McConnell, 1977; Freeman III and Haveman, 1977; McConnell, 1988 and more recently, Boxall et al., 2003). For any of these cases, it is important not to overlook the effects of social congestion cost in natural areas, especially when a relevant part of the economic wealth of the region is originated by the visitors. If congestion is well managed, visitor's satisfaction will be higher and it is more likely that future visits will follow; 
however, if the natural area is crowded, it may deter the possibilities of repeated visits. Hence, if policymakers are interested in promoting and attracting visitors and tourists to the region, the management of the social congestion cost might be considered.

The analysis of social congestion cost will be useful to establish an acceptable limit to the number of visitors that any natural area may receive. Thus, this study is just part of a more complete analysis of congestion cost which would need to determine, on the one hand, the acceptable limit of the number of visitors that the natural area can support in environmental terms which guaranties the sustainability of the natural system and on the other hand, a socially acceptable limit of visitors, which maximise visitor's satisfaction.

In order to regulate (if necessary) the entrance and distribution of visitors among natural areas, policymakers have to take into account different evaluations of the sites. First of all, it is necessary to evaluate environmental carrying capacity of the sites. This is a task commanded to estimate the relationship of the number of visitors and the impact on the sustainability of the site. Once this has been evaluated, we may compare these maximum levels with the current level and design an adequate strategy according to this. Nonetheless, provided a site is within the burdens defined by its environmental carrying capacity, it does not mean that it is within suitable burdens for recreation. An example can be found in beaches where the impacts of visitors on the environment may be sustained for a large number of visitors, such that it is possible that the limit be much larger than what people is willing to accept. In this sense, it is necessary to obtain a social carrying capacity $(S C C)$ index. Such an index may help to monitor the degree of congestion in each natural area (see Prato, 2001 and Lawson et al. 2003)

A relevant issue concerning how to measure congestion is related with the period we choose to measure. The problem is that congestion may vary over time; changing for different months, weeks, days of the week or time of the day. For any period we choose, we can be incurring in a bias. For instance, if we measure congestion in a peak day, it is likely that some potential visitors anticipate crowding and decide either not to travel that day and postpone their visit or recreate in not so popular sites. A similar bias may occur during offpeak days when not all potential visitors can travel. Moreover the problem would be the same if we measure visits in peak (off-peak) days but in different seasons. Furthermore, if we constrain our analysis to a short period, we lose variability in the frequency and destination choices of the interviewees and the estimation becomes poorer. Hence, it seems sensible, in order to avoid seasonality and low variability, to consider the number of visits that the interviewees have done during one year. In order to use yearly measures, we need to assume that there are not significant differences of congestion distribution over the year 
among different destinations, i.e. if, for instance, there is a sunny day, the relative distribution of crowding among natural areas might be similar to the one on a cloudy day. It means that seasonal or weather conditions are not creating special preference for any particular destination, i.e. the vector of oddsratios is assumed to be similar over a year.

\section{BRIEF LITERATURE REVIEW}

\subsection{Congestion bias in environmental valuation}

Most of the discussion during the seventies and the eighties was theoretical and mainly focused on the effects of congestion on environmental valuation techniques, especially the travel cost method. Travel cost technique was at its peak of popularity by that time and congestion is seen as a potential bias for the estimated willingness to pay values. McConnell (1977) considers a utility maximisation framework to deal with congestion. He points out that because of seasonal variations that affect demand and consequently congestion, the employment of aggregate demand is problematic. Moreover, he argues that because in some cases travel costs may be relatively unimportant, travel cost method is likely not to work properly for such situations and suggests the use of contingent valuation studies instead. As responding to McConnell's critics to the travel cost method, Wetzel (1977) opens up a discussion about the way in which congestion may affect consumers' surplus and how congestion should be considered in the utility and demand functions. The discussion focuses on the different demand elasticities obtained taking into account or not the congestion effect. A congestion-varying demand curve is more inelastic because an increase in entrance price will be less effective under the presence of congestion. The price increase may put off some potential visitors who are sensitive to price, but at the same time, such decrease in the number of visitors may also attract other visitors who were not coming due to the previous congestion level (McConnell $(1980,1988)$. McConnell (1980) criticises the difficulties encountered in modelling congestion, especially in generalising the results because the structure of the individual preferences is heterogeneous. Alternative points of view are offered by other participants, such as Stevens and Allen (1980), Anderson (1980), Smith (1981) and Wetzel (1981) who ended up closing the controversy in the literature opened by him. Eventually, the travel cost method was relegated in favour of the contingent valuation technique, thus leaving this debate on hold.

\subsection{Optimal congestion}

According to McConnell (1988), the literature on optimal congestion has evolved in two strains. One based on the economic theory of clubs elaborated by Buchanan (1965), who analyses the issue as if every natural area were a pro- 
fit maximiser agent (see Cornes and Sandler, 1996). For instance, Anderson and Bonsor (1974) deal with congestion within a competitive framework among private clubs which set the optimal level of congestion depending on the trade off between marginal income of one more visitor and the higher marginal congestion cost incurred by the rest of the current visitors. The other strain focuses on the congestion of natural areas, trying to show that unregulated levels of congestion are suboptimal. Within this area, the first works are due to Fisher and Krutilla (1972) and Cicchetti and Smith (1973). Fisher and Krutilla (1972) approach the issue employing functions of benefits net of congestion disutilities and environmental costs due to degradation. Such marginal benefits determine the demand function. Fisher and Krutilla's work had much intuition, although it lacks of a formalised model. In this sense, Freeman III and Haveman (1977) provided a soundly robust and micro-founded model with the consideration of new formalised aspects. They considered the inclusion of heterogeneous tastes among users and a function of willingness to pay for less congested places. Although only from a theoretical point of view, the model determines the optimal level of facility use and has been a reference for most of the following studies. Deyak and Smith (1978) attempt to model congestion within a household production function approach. However, they do not include congestion as part of the utility function of the individuals and thus the analysis seems not to be complete enough. Cesario (1980) develops the concept of 'capacity' and the effects on marginal congestion cost produced by the expansion of existing facilities or by the addition of new ones. A notorious contribution in this field was provided by the existence of functions with thresholds, where within each threshold the congestion level is assumed to be constant. This is known as "constant crowding demand curve" (Anderson and Bonsor, 1974). Dorfman (1984) employs the inverse constant crowding demand curve to obtain consumer surplus, given the usage and capacity levels.

\subsection{Entry access}

Once, it is known that each site requires a control on their capacity, Wanhill (1980) shows how to charge optimally tourist attractions, such that price paid by visitor equals marginal social cost of its visit. Wanhill stresses his analysis for tourist attractions where tourists usually have to queue and model congestion as a function of waiting time. Indeed, once the capacity level is known, there are different alternatives to manage the sites, i.e. with open access, price increases (see McConnell, 1988 for its theoretical consequences) or the use of lotteries (Kerr, 1995).

However, as commented earlier, one way of internalising environmental costs and decreasing congestion is with the introduction of user fees (see this and other alternatives suggested in a tourism context by Knapman and Stoeckl, 
1995; Smeral, 1996; Mananyi, 1998; Fredman and Emmelin, 2001; Tisdell and Wilson, 2001). Concerning pricing policies in nature-based tourism areas, Richardson (2002) distinguishes between local and foreign users, because according to him, the latter have a higher willingness to pay for recreation than domestic users. He also shows that an optimal provision of multiple environmental goods must be based on a differentiated provision of quality for each of them. Alpízar (2006) supports a similar idea of price discrimination among tourists and estimate the optimal entrance fees for different marginal costs. Logar (2010) reviews alternative policy instruments developed for tourism entry access, such as eco-tax, user fee, financial incentives, eco-labels, quotas, zoning, tradable building permits and changes in property rights.

\subsection{Empirical studies}

Despite all the theoretical effort developed during the eighties and nineties, the number of empirical studies concerning congestion is scarce (for instance see Wanhill, 2011, for a review of most researched tourism economics papers). The first contributions concerning congestion pursue the identification and the understanding of the heterogeneity. Noe, Hammitt and Bixler (1997) conduct factor and cluster analyses to estimate the relevance of congestion as compared to other environmental impacts. Jakus and Shaw (1997) employ probit analysis with socioeconomic variables to show the different reactions among users with respect to congestion and the policies to control crowding. Moreover, they define and distinguish between actual, perceived, expected and anticipated congestion. Kerkvliet and Nowell (2000) use destination choice models and the intensity of visits to measure the relevance of the quality of the sites, congestion and accessibility among other factors. They test the hypothesis of crowdingbased self-regulation in relation to congestion. In their anglers' case study, they prove the relevance of congestion. Indeed, in their results, congestion has the second highest elasticity value, only overcome by the elasticity of the hourly catch rate. Heterogeneity remains an important issue in the literature. Boxall, Rollins and Englin (2003) explore not only the presence of heterogeneous preferences but also how different users react under heterogeneous experiences. This is one of the first studies based on contingent valuation ${ }^{1}$. A random utility framework was chosen by Schuhmann and Schwabe (2004) to test the role of expected congestion within a travel cost method. They anticipate that congestion enters utility non-linearly. Timmins and Murdock (2007) point out that the estimation of congestion with a travel cost method is subject to endogeneity problems. They propose the use of quantile regression and instrumental variables to solve it. Bujosa and Rosselló (2007) found out that higher levels of congestion are positively related with greater tolerance by the residents. More

\footnotetext{
${ }^{1}$ They use random parameters probit model.
} 
recently, Santana-Jiménez and Hernández (2011) estimate the effects of population densities as a proxy for congestion. They apply panel data models. The purpose of this paper is to develop a methodology able to provide an indicator of social congestion.

\section{MODELLING}

Modelling in this section comprises three parts. The first part concerns the economic theoretical background, the second part is related with the econometric theoretical contribution and the third part shows the details of the application, such as the dataset employed and the definition of the variables.

\subsection{Tourism destinations as club goods}

Public economics theory of club goods represents an ideal framework for the analysis of the role of congestion in tourism demand and destination choice. Within the tourism context, a club can be defined as a tourist destination. In order to enjoy a club (tourist destination), a potential tourist must pay a price and share the club with the rest of members. The more members a club has, the cheaper the price of the club, but the more congestion they have to face. Such cheaper price may be due to the presence of economies of scale, and even more due to the existence of economies of scope. As explained by Sinclair and Stabler (1997: 85-86), the role of marketing or reservation systems are good examples for potential economies of scope in the tourism industry. Additionally, as the size of the club increases, the market structure may be modified in a way that economies of scale can be translated into larger tourism services provided with higher productivity and or more small companies encouraging any of the two, an eventual decrease in prices. The tradeoff for the tourists is the increase in congestion. The members who are put off by congestion can join any other club or decide to become nonmbers. In general, tourist destinations as club goods are characterised by partial rivalry among members (congestion) and an exclusion mechanism (price).

Club goods theory may be considered from the economywide point of view or from the club members' point of view. The first case maximises the utility of members and non-members, whereas the latter concentrates on the representative member's utility maximisation (Cornes and Sandler, 1996). A basic model from the economywide point of view splits up the utility function into two, depending on their membership status:

Members: $U_{i}=U_{i}\left[y_{i}, v_{i}, c\left(\int_{1}^{s} v_{i} d i, X\right)\right], i \in[1, s]$

Non-members: $\widetilde{U}_{i}=\widetilde{U}_{i}\left[\widetilde{y}_{i}, 0,0\right], i \in[s, \hat{s}]$ 
where $y$ represents private good consumption, $v$ the total number of visits, $c\left(\int_{1}^{s} v_{i} d i, X\right)$ is a congestion function that depends on the club's total visitation rate $\int_{1}^{s} v_{i} d i$ and the capacity constraint $X$. Membership size of the club $s$ is measured as a participation rate in relation to the population size $\hat{s}$.

Using a weighted Benthamite social welfare function, optimal provision, toll and membership conditions are derived (Cornes and Sandler, 1996). Extensions of this model can consider uncertainty (Sandler, Sterbenz and Tschirhart, 1985) concerning the probability of visiting a congested destination and intergenerational clubs (Sandler, 1982) for the case of sustainable tourism development. Despite the theoretical effort concerning the congestion issue, there is still a lack of applied work in this area. This paper pursues a step forward in this sense, trying to fill that gap combining the utility function approach with the utility-based econometric models. This is the purpose of the following model.

\subsection{Congestion index}

Definition. Congestion level, denoted by $C_{s}$, is the ratio between the number of visitors, denoted by $V_{s}$, and a capacity constraint, denoted by $K_{s}$, $C_{s}=\frac{V_{s}}{K_{s}}$, where capacity constraints may be measured in length, area, or number of available units depending on the nature of the site and the kind of activity that visitors undertake.

Any individual, labelled $i$, may decide to visit a site or not. Once an individual has decided to visit, he or she chooses the site $s$, among his or her choice set.

Assumption 1. The choice set consists of a finite number of mutually exclusive competitive destinations $n$, such that $n>0$.

In order to model the destination choice, we follow a behavioural model where the individual chooses the destination that provides the highest level of utility, denoted by $U$. In this sense, individual $i$ would choose site $s$ if and only if: $U_{i s}>U_{i t} \forall t \neq s$. Nevertheless, these utility levels are unobservable. The only aspects known are some socioeconomic characteristics of the individuals, denoted by $S_{i}$, and some attributes of the set of sites, denoted by $A_{s}$, where $C_{s} \in A_{s}$. From the information available, we can construct a function $V_{i s}=V\left(S_{i}, A_{s}\right) \forall s$, which represents the utility that site $s$ provides to individual 
$i$. Thus, utility can be decomposed as: $U_{i s}=V_{i s}+\varepsilon_{i s}$, where $\varepsilon_{i s}$ denotes the unobserved part of utility for individual $i$ when he or she visits site $s$. Then, the probability that an individual $i$ chooses to visit site $s$ is:

$$
P_{i s}=\operatorname{Pr}\left(U_{i s}>U_{i t} \forall t \neq s\right)=\operatorname{Pr}\left(V_{i s}+\varepsilon_{i s}>V_{i t}+\varepsilon_{i t} \forall t \neq s\right)=\operatorname{Pr}\left(\varepsilon_{i t}-\varepsilon_{i s}<V_{i s}-V_{i t} \forall t \neq s\right)
$$

In logit models the whole error or part of it is assumed to be independently and identically distributed extreme value. As reported by Train (2003), within a random parameter logit model (RPLM), the probability that an individual $i$ visits site $s$ is given by: $P_{i s}=\int\left(e^{V_{i s}(\beta)} / \sum_{t} e^{V_{i t}(\beta)}\right) f(\beta) \mathrm{d} \beta$ where $\beta$ is the vector of parameters associated with each component of the utility function and $f(\beta)$ is the mixing distribution, which allows for modelling heterogeneous concern of visitors about congestion.

Assumption 2. Utility is linear in $\beta$.

Under assumption 2, probability can be written as: $P_{i s}=\int\left(e^{\beta^{\prime} x_{i s}} / \sum_{t} e^{\beta^{\prime} x_{i t}}\right) f(\beta) \mathrm{d} \beta$. This assumption constrains the scope of the analysis to the short run.

In order to measure the sensitivity of heterogeneous visitors to congestion increases, the elasticity of congestion from a RPLM is proposed. An advantage of the elasticity measure is that it is fully comparable over alternatives because it is a normalised measure. The components of the elasticity are stated in Lemma 1.

Lemma 1. Elasticity of congestion within a random parameter logit framework depends on the current level of congestion, the sensitivity of the utility function under increases in congestion levels and the probabilities of visiting alternative destinations.

$$
\begin{aligned}
& \text { Proof } \\
& \qquad E C_{i s}=\frac{\partial P_{i s}}{\partial C_{s}} \frac{C_{s}}{P_{i s}}, \text { since } \frac{\partial P_{i s}}{\partial C_{s}}=\int\left(\frac{\left(\beta^{C} e^{\beta^{\prime} x_{i s}}\right)\left(\sum_{t} e^{\beta^{\prime} x_{i t}}\right)-\beta^{C} e^{2 \beta^{\prime} x_{i s}}}{\left(\sum_{t} e^{\beta^{\prime} x_{i t}}\right)^{2}}\right) f(\beta) \mathrm{d} \beta
\end{aligned}
$$




$$
\begin{aligned}
& E C_{i s}=\frac{\partial P_{i s}}{\partial C_{s}} \frac{C_{s}}{P_{i s}}=\int C_{s}\left(\frac{\left(\beta^{C} e^{\beta^{\prime} x_{i s}}\right) /\left(\sum_{t} e^{\beta^{\prime} x_{i t}}\right)}{\left(e^{\beta^{\prime} x_{i s}}\right) /\left(\sum_{t} e^{\beta^{\prime} x_{i t}}\right)}-\frac{\left(\beta^{C} e^{2 \beta^{\prime} x_{i s}}\right) /\left(\sum_{t} e^{\beta^{\prime} x_{i t}}\right)^{2}}{\left(e^{\beta^{\prime} x_{i s}}\right) /\left(\sum_{t} e^{\beta^{\prime} x_{i t}}\right)}\right) f(\beta) \mathrm{d} \beta \\
& E C_{i s}=\int C_{s}\left(\beta^{C}-\beta^{C} e^{\beta^{\prime} x_{i s}} / \sum_{t} e^{\beta^{\prime} x_{i t}}\right) f(\beta) \mathrm{d} \beta=E C_{i s}=\int C_{s} \beta^{C}\left(1-P_{i s}\right) f(\beta) \mathrm{d} \beta
\end{aligned}
$$

As stated in lemma 1, the elasticity of congestion is a sensible measure of the sensitivity of visitors to congestion because it takes into account the current level of congestion $\left(C_{S}\right)$, the sensitivity of the utility function under increases in congestion $\left(\beta^{C}\right)$ and the probabilities of visiting alternative destinations (1- $\left.P_{i s}\right)$. Moreover within RPLM, heterogeneous concern about congestion is considered through the mixing distribution $f(\beta)$. At one extreme, each visitor may have his or her own sensitivity to congestion and the RPLM is applicable. At the other extreme, it may be assumed that all visitors are equally sensitive to congestion, such that the mixing distribution will follow a uniform distribution and the multinomial logit model (MLM) is applied. In between, alternative models as latent class models (LCM) may consider a limited number of different kinds of visitors (one per class). Both MLM and LCM are particular cases of the random parameter logit approach and the application of the results to these models is straightforward. Congestion measures for each kind of model are reported in Table 1.

Table 1

\begin{tabular}{|c|c|c|}
\hline & Properties & Measurement \\
\hline Traditional method & $\begin{array}{l}\text { Linear and independent of } \\
\text { alternatives. }\end{array}$ & $C_{s}$ \\
\hline Multinomial Logit & $\begin{array}{l}\text { Non-linear and it considers other } \\
\text { alternatives. }\end{array}$ & $C_{s} \beta^{C}\left(1-P_{i s}\right)$ \\
\hline Latent Class & $\begin{array}{l}\text { Non-linear, it considers other } \\
\text { alternatives and up to } n \text { different } \\
\text { heterogeneous categories of } \\
\text { visitors. }\end{array}$ & $\sum_{j=1}^{n} C_{s} \beta_{j}^{C}\left(1-P_{i s}\right) / n$ \\
\hline Random Parameter Logit & $\begin{array}{l}\text { Non-linear, it considers other } \\
\text { alternatives and each individual } \\
\text { with his/her heterogeneous } \\
\text { sensitivity towards congestion. }\end{array}$ & $C_{s} \beta^{C}\left(1-P_{i s}\right) f(\beta) \mathrm{d} \beta$ \\
\hline
\end{tabular}

Measures of congestion by econometric model

Source: Own elaboration. 


\subsection{Dataset}

The dataset was built for understanding the destination choice of climbers and trekkers in the North-Eastern Italian Alps. The region is divided for estimation purposes into 18 different destinations of mountains which define the choice set. The behavioural data on climbing trips was collected with a survey from a sample of 549 rock-climbers members of the Italian Alpine Club or CAI, who reported on their last year of climbing activities. Data were collected by using a mail questionnaire. Climbers were asked questions about their climbing abilities and experience, whether they attended mountaineering training course; the average training in cliffs and indoor climbing walls; average numbers of climbs completed per year; years climbing; average climbing grade; other activities practised as hill-walking and ski-mountaineering.

They also have been asked the total trips in the last twelve months to each of the 18 sites. Finally, climbers were asked to provide socio-economic information. Round-trip distance from own residence to each of the destination in the choice set was calculated using the soft package "Strade d'Italia e d'Europa". This data was used to estimate the individual travel cost for each trip. Distance costs were converted to money using a figure of 0.35 Euro. It is assumed that each trip taken was a "one day out" trip, as customary for this activity. The dataset was collected by Mara Thiene and further information on data collection, variables and modelling can be found in different papers, see for instance Thiene and Scarpa (2008) or Thiene and Scarpa (2009).

Since any destination possesses its own attributes, it is plausible to think that each one offers a different level of utility. Moreover, since any user is different from each other, it is expected that the same site will also offer a different level of utility by user because the characteristics and different tastes of them are influencing the enjoyability of each site. Taking these general and relative aspects into account, we can presume that any user will choose the site that maximises his or her utility function, depending on:

\subsubsection{General variables}

- Travel cost

It is assumed that time range to each destination choice is for a single day trip. Clearly, the further the site is for the visitor, the more costly it will be for him or her to travel there, both in terms of transportation cost and travel time cost and hence the less likely to choose ${ }^{2}$.

\footnotetext{
${ }^{2}$ Some authors, as Cesario (1976), have tried to decompose the travel cost into transportation cost and travel time cost using estimates from transportation surveys.
} 
- Attractiveness of the site:

- Average height of the site

- Accessibility to the site

- Variety of the flora

- Percentage of vegetation in the area

- Number of alternative routes available

\subsubsection{Relative variables}

- Suitability of the destination for the visitor

Some sites may be difficult to walk or climb and consequently, be attractive for habitual climbers. However, at the same time this difficulty can also be seen as not attractive at all by occasional or inexpert climbers. In order to measure this heterogeneity on the preferences of different users, we can employ a loss function defined as:

Loss function relative to the level of difficulty: $l_{d i s}=\left(D F_{s}-D_{i}\right)^{2} \forall i, s$, where $D F_{s}$ means difficulty of the site $s$, and $D_{i}$ means ideal level of difficulty for user $i$. Loss function relative to the level of adequacy of routes: $l_{\text {ris }}=\left(D R_{s}-D_{i}\right)^{2} \forall i, s$, where $D R_{s}$ means level of adequacy of route of the site $s$. Moreover, in order to avoid multicollinearity problems with these two loss functions a joint loss function of difficulty is defined such as $l_{i s}=l_{d i s}+l_{\text {ris }}$.

- Travel cost as a percentage of total income

It is defined by: $C I_{i s}=\frac{C_{i s}}{I_{i}} \forall i, s$, where $C_{i s}$ means travel cost for individual $i$ to site $s$ and $I_{i}$ denotes income of individual $i$.

- Frequency of use

Although any visitor may have a favourite site, the decreasing marginal utility of a trip to a specific place, increases the chances of going to other sites.

- Other characteristics of the individual considered

These are characteristics which discriminate among individuals and try to minimise their taste differences. For instance, they have been categorised in terms of habitual or occasional alpinist, habitual or occasional excursionist, alpine skier, ski alpinist, instructor or guide. Additional information concerning education and preparation is considered, such as if the climber has taken alpinist courses or the kind of gym preparation carried out to face the climbing. Furthermore, socioeconomic characteristics such as age, gender and the number of years practicing climbing are also taken into account. 


\section{RESULTS}

\subsection{Multinomial Logit Model}

\subsubsection{Whole sample}

As commented in the previous sections, the purpose is to obtain the elasticity of demand with respect to congestion. The results are shown in Table 2. Considering the whole sample, travel cost and loss function of suitability of the destination for the visitor are negatively related with the number of visits. Moreover, it is shown that since most of the visitors are alpinist or climbers, on average, the percentage of vegetation is not an attractive aspect of the destinations, whereas height average and difficulty level of the site are. Also, as expected, the accessibility of the sites and the number of available routes are considered positively by the visitors.

Table 2

Model I: Multinomial logit model of the whole sample

\begin{tabular}{lrrrr}
\hline \multicolumn{1}{c}{ Variables } & Coefficient & Std. error & t-ratio & P-value \\
\hline Travel cost & -0.5138 & 0.0332 & -15.4953 & 0.0000 \\
(Cost / Income) & 0.0018 & 0.0007 & 2.5699 & 0.0102 \\
Height average & 0.0009 & 0.0002 & 3.7650 & 0.0002 \\
Vegetation (\%) & -0.0407 & 0.0079 & -5.1653 & 0.0000 \\
Difficulty level & 1.3459 & 0.1469 & 9.1597 & 0.0000 \\
Accessibility & 0.5930 & 0.0992 & 5.9800 & 0.0000 \\
Severity & -1.2779 & 0.2242 & -5.6993 & 0.0000 \\
Loss function of difficulty & -0.0430 & 0.0046 & -9.4389 & 0.0000 \\
Number of routes & 0.4539 & 0.0580 & 7.8246 & 0.0000 \\
\hline
\end{tabular}

Source: Own elaboration.

A remarkable finding is that the travel cost of the trip as a percentage of income is positively related with demand. This suggests that as income increases, on average, visitors prefer not to spend their leisure time in outdoor recreation activities. Thus we can ask ourselves whether outdoor recreation is an inferior good or not. This is an interesting issue that would require further analysis. Another relevant finding is the fact that social congestion cost is not significant. Nevertheless, this is due to the existence of heterogeneity among visitors. What is happening is that there are some visitors who care about congestion and others who do not. On average, it becomes insignificant, but 
what we need to know is how the pattern for these two different groups is. We can split up the sample and run two different models, one for those who are affected by congestion and another one for those who are not. These two models are presented in Table 3 and Table 4.

\subsubsection{Indifferent to congestion}

The sample contains 548 observations. From this sample, 211 interviewees consider that congestion affects negatively their recreation satisfaction, whereas the rest 337 individuals do not. Since both subsamples are large enough, it is feasible to split up the sample and model them separately. This provides a first approach to see if there is a significant different behaviour between the two market segments.

Table 3

Model II: Multinomial logit model of visitors not affected by congestion

\begin{tabular}{lrrrr}
\hline \multicolumn{1}{c}{ Variable } & Coefficient & Std. error & t-ratio & P-value \\
\hline Travel cost & -0.6064 & 0.0421 & -14.4164 & 0.0000 \\
(Cost / Income) & 0.0039 & 0.0009 & 4.4038 & 0.0000 \\
Accessibility & 0.1502 & 0.0514 & 2.9195 & 0.0035 \\
Number of routes & 0.2586 & 0.0290 & 8.9249 & 0.0000 \\
\hline
\end{tabular}

Source: Own elaboration.

Considering only those visitors who are not influenced by congestion, we end up with the model of Table 3. The higher concern of these kinds of users is apart from the travel cost, the number of available routes and the accessibility levels to the site. It is remarkable that these users feel indifferent to the degree of congestion.

\subsubsection{Sensitive to congestion}

Clearly in Table 4 the model shows remarkable differences between both kinds of users. While visitors who are not concerned about congestion were deciding their destination choice depending on easy access to the site, visitors who care about congestion are more willing to go to places where access is more difficult. On average, they prefer high natural areas, uncongested, which are difficult to walk and access. It is remarkable that for this subsample, congestion becomes significant (-0.0004), which proves the hypothesis of heterogeneity of users in natural areas with respect to social congestion cost. 
Table 4

Model III: Multinomial logit model of visitors affected by congestion

\begin{tabular}{lcccc}
\hline \multicolumn{1}{c}{ Variable } & Coefficient & Std. error & t-ratio & P-value \\
\hline Travel cost & -0.4292 & 0.0130 & -32.991 & 0.0000 \\
Height average & 0.0009 & 0.0003 & 3.543 & 0.0004 \\
\% of vegetation & -0.0260 & 0.0098 & -2.656 & 0.0079 \\
Level of difficulty & 0.7465 & 0.0833 & 8.965 & 0.0000 \\
Level of accessibility & -0.6283 & 0.1517 & -4.140 & 0.0000 \\
Congestion & -0.0004 & 0.0002 & -1.983 & 0.0474 \\
Loss function of difficulty & -0.0235 & 0.0039 & -6.092 & 0.0000 \\
\hline
\end{tabular}

Source: Own elaboration.

The main results of this work are those related with the elasticity of social congestion cost. These are shown in Table 5. The largest elasticity corresponds to site 2 , with a value of -0.696 , this is not surprising because this site is also the most visited. However one of the lowest values of elasticity belongs to site 1, with a value of -0.086 . It is interesting because site 1 is the third most visited natural area, but the ratio of visitors is very low. These results support our hypothesis of the relevance of elasticity as a tool for monitoring congestion. Also in Table 5 it is shown the elasticity of the other destinations with respect to an increase in congestion cost in the site. This is interesting if we are considering chain effects on the other sites. It is particularly important in Table 5, where cross elasticities can be used as a reference for indirect effects on demand with respect to changes in the travel cost, as improved roads, construction of bridges or tunnels. For instance, we can see that site 2 is also very sensitive to increases in travel cost. It means that if visitors need to incur in any extra travel cost when accessing to site 2 , then it is likely that many potential visitors would prefer to go to any other destination. Some authors have argued that we can use this variable also to determine marginal effects of changes in the entrance fees. However, we consider that travel cost would need to be decomposed between transportation cost and travel time cost in order to obtain a more realistic result. 
Table 5

Inter-relationships between $R V, E C$ and $E T C$

\begin{tabular}{|c|c|c|c|c|c|c|}
\hline SITE & $\begin{array}{l}\text { Number of } \\
\text { visitors }\end{array}$ & $\begin{array}{l}\text { Ratio of } \\
\text { visitors per } \\
\text { length of } \\
\text { marked path } \\
R V\end{array}$ & $\begin{array}{c}\text { Elasticity of } \\
\text { congestion } \\
E C\end{array}$ & $\begin{array}{l}\text { Cross } \\
\text { elasticity with } \\
\text { respect to } \\
\text { other } \\
\text { destinations }\end{array}$ & $\begin{array}{c}\text { Elasticity of } \\
\text { travel cost } \\
\text { ETC }\end{array}$ & $\begin{array}{l}\text { Cross } \\
\text { elasticity with } \\
\text { respect to } \\
\text { other } \\
\text { destinations }\end{array}$ \\
\hline 1 & 137,669 & $\underline{0.28}$ & -0.086 & 0.008 & -1.573 & 0.148 \\
\hline 2 & 261,593 & 45.54 & -0.696 & 0.135 & -1.952 & 0.378 \\
\hline 3 & 67,952 & 2.84 & -0.226 & 0.012 & -1.800 & 0.099 \\
\hline 4 & 130,097 & 1.58 & -0.197 & 0.010 & -1.711 & 0.086 \\
\hline 5 & 105,502 & 4.03 & -0.170 & 0.008 & $\underline{-1.171}$ & $\underline{0.055}$ \\
\hline 6 & 164,607 & 3.71 & -0.233 & 0.016 & -2.215 & 0.150 \\
\hline 7 & 33,414 & 11.19 & -0.363 & 0.009 & -2.445 & $\underline{0.059}$ \\
\hline 8 & 35,520 & 52.51 & -0.460 & 0.016 & -2.439 & 0.084 \\
\hline 9 & 47,711 & $\underline{0.86}$ & $\underline{-0.070}$ & $\underline{0.003}$ & -3.083 & 0.132 \\
\hline 10 & $\underline{10,643}$ & 2.15 & -0.090 & $\underline{0.001}$ & -2.281 & $\underline{0.027}$ \\
\hline 11 & $\underline{20,693}$ & 6.97 & -0.161 & 0.003 & -2.945 & 0.058 \\
\hline 12 & $\underline{22,153}$ & 0.88 & $\underline{-0.055}$ & $\underline{0.001}$ & -2.474 & 0.045 \\
\hline 13 & 36,263 & $\underline{0.68}$ & $\underline{-0.060}$ & 0.002 & -1.968 & 0.067 \\
\hline 14 & 36,955 & 2.14 & -0.139 & 0.005 & -2.671 & 0.101 \\
\hline 15 & 104,044 & 11.89 & -0.361 & 0.037 & -2.870 & 0.297 \\
\hline 16 & 111,929 & 4.53 & -0.251 & 0.030 & -2.347 & 0.276 \\
\hline 17 & 105,698 & 5.07 & -0.295 & 0.029 & -1.870 & 0.181 \\
\hline 18 & 50,104 & 4.06 & -0.128 & 0.005 & -3.236 & 0.133 \\
\hline
\end{tabular}

Note:

Bold font refers to those sites with the three highest values

Underline and cursive font refers to the sites with the three lowest values

Source: Own elaboration.

\subsection{Mixed Logit Model}

Previous sections have proved the existence of heterogeneity in relation to congestion awareness. Two different segments have been identified. One market segment is not concerned about congestion, whereas the other market segment is particularly sensitive to congestion levels. This result suggests the presence of a random parameter related to congestion, depending on the sensitivity of the individual towards congestion. Hence, a random parameters Logit model (Mixed Logit) is run in order to test such hypothesis. Congestion is the only variable with a random parameter. This was tested to follow different probability functions. The best fit was provided with a prior uniform distribution. 
The estimated parameters of the Mixed Logit model are similar to MNL (whole sample) model I with the difference that now congestion is associated with a significant random parameter. The estimated value of the congestion parameter is negative, but very close to zero. However, its value can only be understood in conjuction with another two parameters, the heterogeneity in mean and the derived standard deviation of the parameter distribution (see Hensher, Rose and Greene, 2005). It is even more illustrative to consider a Kernel distribution of the estimated parameter for the whole population. This is shown in Figure 1. It reflects the heterogeneity towards congestion. Many users are indifferent to the level of congestion, whereas other users are clearly more affected positively or negatively.

Figure 1

Kernel distribution of random congestion parameter (whole sample)

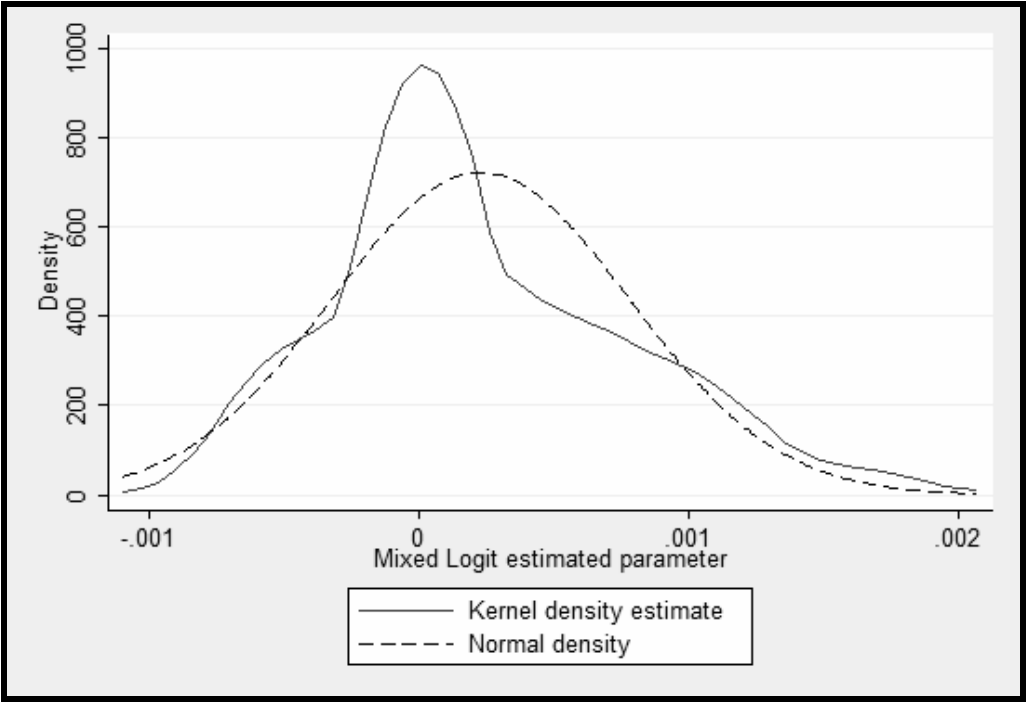

Source: Own elaboration.

Figure 2 represents only the Kernel distribution of the congestion parameter of those who are affected by congestion (negative beta). The estimated parameter from the multinomial logit model III (-0.0004) estimated from the subsample of those individuals who are affected by congestion is lower than the estimated parameter from the mixed logit model (-0.00023) obtained from the whole population. If the latter parameter is used to obtain the elasticity values of Table 5, the results should be around half of the previous results. This is due to the fact that the mixed logit parameter considers now the whole population. The 
remaining question is which one should be used to measure congestion and social carrying capacity indices.

Figure 2

Kernel distribution of random congestion parameter

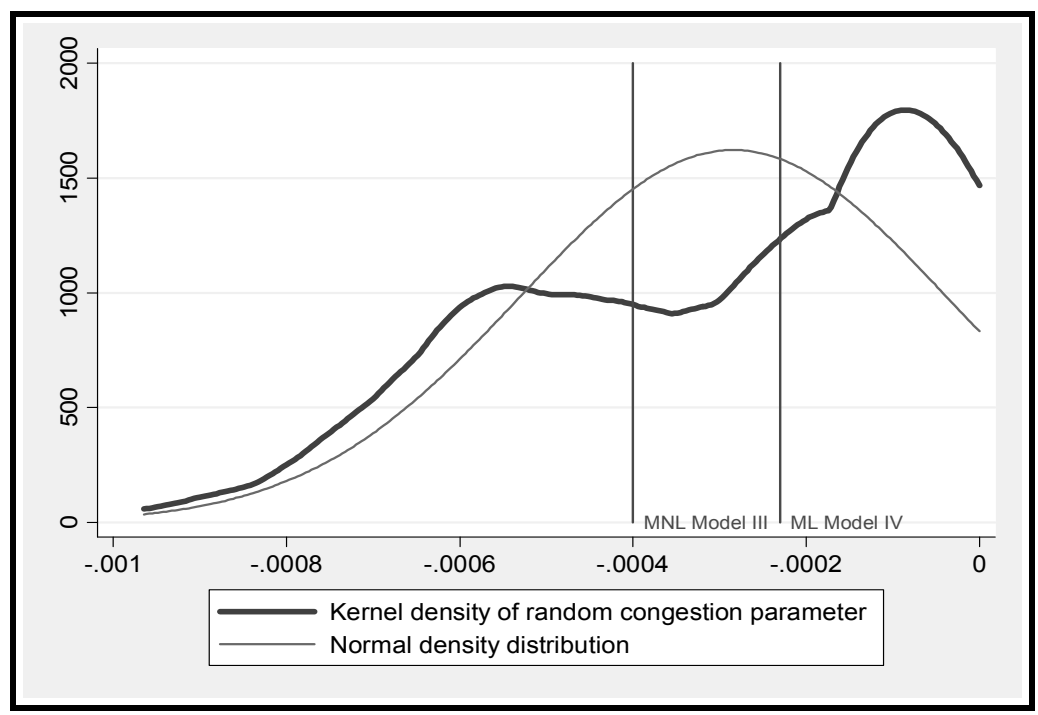

Source: Own elaboration.

\section{CONCLUSIONS}

Features of the elasticity of congestion make it particularly useful for capturing changes in the sensitivity of individuals to increases in congestion. Within a random parameter logit framework, this measure takes into account the heterogeneity of visitors and destinations with respect to congestion, the current level of congestion and the current probabilities of visiting alternative sites. Under increases in the number of visitors, it captures the increasing sensitivity to congestion as a non-linear function. Hence, this elasticity can be used as a comprehensive congestion index to monitor the sensitivity of visitors with respect to higher degrees of congestion in different areas, which is a more realistic measure than the traditional ratio of visitors. The purpose of such monitoring is to estimate the additional capacity of the destinations. However, this paper proves that this social carrying capacity does not correspond to a static measure, but dynamic, in the sense that congestion is a relative measure that depends on the situation of the alternative destinations. Moreover, the social carrying capacity of a set of destinations also depends on the relative attractiveness of further destinations or alternative ways of spending the spare time. The elasticity of 
congestion, when combined with cross elasticities of other destinations and with the elasticities of travel cost allows for creating a system of interconnected elasticities. This system becomes very useful to predict the effects and interrelations of any variation in any of the attributes of the sites. For instance, cross elasticities of congestion permit simulations of the consequences of changes in the congestion level of one particular destination, because it reveals the degree of the interconnection of the destinations in terms of flows of visitors. Furthermore, the elasticity of the travel cost, when combined with changes in congestion, may also be relevant to evaluate entrance fees policies or to anticipate variations in congestion under any improvement in the accessibility to the destinations.

Concerning the results of the sample considered, the paper shows the existence of heterogeneity in preferences for congestion. Two classes of visitors are identified. One class is concerned with the presence of congestion, whereas the other class is not. Splitting up the sample into these two classes, and running different multinomial logit models, provide a significant parameter to the congestion level for the class of visitors affected by congestion, but insignificant to those not affected. Hence, the elasticity of congestion take a negative value for those visitors who are affected by congestion but it cannot be evaluated for the other class of visitors. An intermediate solution is obtained with the use of random parameter logit modelling when applied to the whole population. As expected, it provides an average congestion parameter estimate lower than the one obtained from the multinomial logit model using the subsample of visitors affected by congestion. Indeed, it provides a distribution of such parameter which it is similar to a Normal distribution with roughly half of the population negatively affected by congestion and the other half positively affected. These results can also be fully understood in combination with the context of the activity and the sort of destination. In the climbers' case, congestion is seen positively by beginners. It makes sense if they want to minimise the risk. For this purpose, it is better to be surrounded by other visitors and also places with higher accessibility are preferred in the hypothetical case of suffering any accident.

Multiple issues require further research. From the theoretical point of view it is necessary to associate the congestion index with a real number of visitors, such that the remaining capacity can be estimated. Further use of the theory of club goods for the intergenerational use of destinations is a promising way to model sustainable tourism development. From the empirical point of view, the role that endogeneity of congestion plays in the estimation results also requires further research. If current congestion is anticipated by the visitors, then congestion can be seen as an additional attribute of a destination. However, at the same time, congestion is the aggregate of the set of all these individual decisions. 


\section{REFERENCES}

ALPÍZAR, F. (2006): "The pricing of protected areas in nature-based tourism: A local perspective” en Ecological Economics, 56: pp. (294-307).

ANDERSON, F.J. and N.C. BONSOR (1974): "Allocation, congestion and the valuation of recrational resources", en Land Economics, 50: pp. (51-57).

ANDERSON, L.G. (1980): "Estimating the benefits of recreation under conditions of congestion: Comments and extension" en Journal of Environmental Economics and Management, 7: pp. (401-416).

BOXALL, P.; K. ROLLINS and J. ENGLIN (2003): "Heterogeneous preferences for congestion during a wilderness experience" en Resource and Energy Economics, 25: pp. (177-195).

BUCHANAN, J.M. (1965): "An economic theory of clubs" en Economica, 32: pp. $(1-14)$.

CESARIO, F.J. (1976): "Value of time in recreation benefit studies" en Land Economics, 51(2): pp. (32-41).

CESARIO, F.J. (1980): "Congestion and the valuation of recreation benefits" en Land Economics, 56(3): pp. (329-338).

CICCHETTI, C.J. and V.K. SMITH (1973): "Congestion, quality deterioration and optimal use: Wilderness recreation in the Spanish Peaks primitive area" en Social Science Research, 2: pp. (15-30).

CORNES, R. and T. SANDLER (1996): The theory of externalities, public goods and club goods, second edition, Cambridge: Cambridge University Press.

DEYAK, T. and V.K. SMITH (1978): "Congestion and participation in outdoor recreation: A household production function approach" en Journal of Environmental Economics and Management, 5: pp. (63-80).

DORFMAN, R. (1984): "On optimal congestion" en Journal of Environmental Economics and Management, 11: pp. (91-106).

FISHER, A. and J.V. KRUTILLA (1972): "Determination of optimal capacity of resource-based recrational facilities" en Natural Resources Journal, 12: pp. (417-444).

FREDMAN, P. and L. EMMELIN (2001): "Wilderness purism, willingness to pay and management preferences: a study of Swedish mountain tourists" en Tourism Economics, 7(1): pp. 5-20.

FREEMAN III, A.M. and R.H. HAVEMAN (1977): "Congestion, quality deterioration, and heterogeneous tastes" en Journal of Public Economics, 8: pp. (225-232).

HENSHER, D.A., J.M. ROSE and W. H. GREENE (2005): Applied choice analysis: A primer, Cambridge: Cambridge University Press. 
JAKUS, P.M. and D.W. SHAW (1997): "Congestion at recreation areas: empirical evidence on perceptions, mitigating behaviour and management preferences" en Journal of Environmental Management, 50: pp. (389-401).

KERKVLIET, J. and C. NOWELL (2000): "Tools for recreation management in parks: the case of the greater Yellowstone's blue-ribbon fishery" en Ecological Economics, 34: pp. (89-100).

KERR, G.N. (1995): "Managing congestion: Economics of price and lottery rationing" en Journal of Environmental Management, 45: pp. (347-364).

KNAPMAN, B. and N. STOECKL (1995): "Recreation user fees: an Australian empirical investigation" en Tourism Economics, 1(1): pp. (5-15).

LAWSON, S.R.; R.E. MANNING; W.A. VALLIERE and B. WANG (2003): "Proactive monitoring and adaptive management of social carrying capacity in Arches National Park: an application of computer simulation modeling" en Journal of Environmental Management, 68: pp. (305-313).

LOGAR, I. (2010): "Sustainable tourism management in Crikvenica, Croatia: An assessment of policy instruments" en Tourism Management, 31: pp. (125135).

MANANYI, A. (1998): "Optimal management of ecotourism" en Tourism Economics, 4(2): pp. (141-169).

MCCONNELL, K.E. (1977): "Congestion and willingness to pay: A study of beach use" en Land Economics, 53(2): pp. (185-195).

MCCONNELL, K.E. (1980): "Valuing congested recreation sites" en Journal of Environmental Economics and Management, 7: pp. (389-394).

MCCONNELL, K.E. (1988): "Heterogeneous preferences for congestion" en Journal of Environmental Economics and Management, 15: pp. (251-258).

NOE, F.P.; W.E. HAMMITT and R.D. BIXLER (1997): "Park user perceptions of resource and use impacts under varied situations in three national parks" en Journal of Environmental Management, 49: pp. (323-336).

PRATO, T. (2001): "Modeling carrying capacity for national parks" en Ecological Economics, 39: pp. (321-331).

RICHARDSON, M. (2002): "Quality and congestion in environmental goods. The road to the Wangapeka" en Journal of Environmental Economics and Management 43: pp. (477-496).

ROSSELLÓ, J. and A. BUJOSA (2007): "Attitudes toward tourism and tourism congestion" en Région et Dévelopment, 25: pp. (193-207).

SANDLER, T. (1982): "A theory of intergenerational clubs" en Economic Inquiry, 20: pp. (191-208).

SANDLER, T., F.P. STERBENZ and J. TSCHIRHART (1985): "Uncertainty and clubs" en Economica, 52: pp. (467-477).

SANTANA-JIMENEZ, Y. and J.M. HERNANDEZ (2011): "Estimating the effect of overcrowding on tourist attraction: The case of Canary Islands" en Tourism Management, 32(2): pp. (415-425). 
SAVERIADES, A. (2000): "Establishing the social tourism carrying capacity for the tourist resorts of the east coast of the Republic of Cyprus" en Tourism Management, 21(2): pp. (147-156).

SCHUHMANN, P.W. and K.A. SCHWABE (2004): "An analysis of congestion measures and heterogeneous angler preferences in a random utility model of recreational fishing" en Environmental and Resource Economics, 27: pp. (429-450).

SINCLAIR, M.T. and M. STABLER (1997): The economics of tourism, London: Routledge.

SMERAL, E. (1996): "Economic policy measures for reducing the environmental impact of tourism" en Tourism Economics, 2(2): pp. (173-184).

SMITH, V.K. (1981): "Congestion, travel cost recreational demand models, and benefit valuation" en Journal of Environmental Economics and Management 8: pp. (92-96).

STEVENS, T.H. and P.G. ALLEN (1980): "Estimating the benefits of recreation under conditions of congestion" en Journal of Environmental Economics and Management, 7: pp. (395-400).

THIENE, M. and R. SCARPA (2008): "Hiking in the Alps: exploring substitution patterns of hiking destinations" en Tourism Economics, 14(2): pp. (263-282).

THIENE, M. and R. SCARPA (2009): "Deriving and testing efficient estimates of WTP distributions in destination choice models" en Environmental and Resource Economics, 44(3): pp. (379-395).

TIMMINS, C. and J. MURDOCK (2007): "A revealed preference approach to the measurement of congestion in travel cost models" en Journal of Environmental Economics and Management, 53: pp. (230-249).

TISDELL, C. and C. WILSON (2001): "Wildlife-based tourism and increased support for nature conservation financially and otherwise: evidence from sea turtle ecotourism at Mon Repos" en Tourism Economics, 7(3): pp. (233-249).

TRAIN, K. (1998): "Recreation demand models with taste variation over people" en Land Economics, 74(2): pp. (230-239).

TRAIN, K. (2003): Discrete Choice Methods with Simulation, Cambridge: Cambridge University Press.

WANHILL, S.R.C. (1980): "Charging for Congestion at Tourists Attractions" en International Journal of Tourism Management, 1: pp. (168-174).

WANHILL, S.R.C. (2011): "What tourism economists do. Their contribution to understanding tourism" en Estudios de Economía Aplicada, 29(3), forthcoming.

WETZEL, J.N. (1977): "Estimating the benefits of recreation under conditions of congestion" en Journal of Environmental Economics and Management, 4: pp. (239-246).

WETZEL, J.N. (1981): "Congestion and economic valuation: A reconsideration" en Journal of Environmental Economics and Management, 8: pp. (192-195). 